\title{
Aconselhamento em saúde: fatores terapêuticos em grupo de apoio psicológico para transtornos alimentares
}

\author{
Counseling in health: Therapeutic factors in a psychological \\ support group for eating disorders
}

\author{
Manoel Antônio dos SANTOS ${ }^{1}$ \\ Fabio SCORSOLINI-COMIN² \\ Elaine Cristina da Silva GAZIGNATO3
}

\begin{abstract}
Resumo
Este estudo teve como objetivo identificar fatores terapêuticos em um grupo de apoio para pacientes com transtornos alimentares (anorexia e bulimia). O grupo de apoio psicológico é parte da estratégia de assistência oferecida por um serviço especializado em saúde. Duas sessões, com um total de 10 participantes, foram audiogravadas e transcritas na íntegra. A análise de conteúdo temática evidenciou que, ao reconhecerem na experiência alheia aspectos semelhantes aos seus próprios problemas, os participantes puderam se identificar uns com os outros e construir um espaço homogeneizado pela normalização das dificuldades. Além disso, os participantes mencionaram que o grupo promove esperança, conforto e bem-estar a partir do compartilhamento de experiências vitais. Desse modo, universalidade e instilação de esperança foram os principais fatores terapêuticos de apoio ativados nas sessões grupais, contribuindo para potencializar processos de mudança em uma perspectiva ampliada de saúde.
\end{abstract}

Palavras-chave: Anorexia nervosa; Bulimia nervosa; Fatores terapêuticos; Grupos de apoio; Psicoterapia de grupo; Transtornos alimentares.

\begin{abstract}
This study aimed to identify therapeutic factors in a support group for patients with eating disorders (anorexia and bulimia). Psychological support groups compose part of the strategy of assistance offered by a specialized health service. Two group sessions with 10 participants were audio recorded and transcribed in full. Thematic content analysis showed that, the participants recognized similar aspects of their own problems in the experience of others, and could identify with each other and construct a space homogenized by standardization of the difficulties. In addition, the participants mentioned that the group promotes hope, comfort and well-being through the sharing of life experiences. Thus, universality and instillation of hope were the main therapeutic factors activated in the group sessions, helping to improve the process of change in a broad perspective of health.
\end{abstract}

Keywords: Anorexia nervosa; Bulimia nervosa; Therapeutic factors; Support groups; Psychotherapy group; Eating disorders.

$\boldsymbol{v} \boldsymbol{\nabla} \boldsymbol{v}$

${ }^{1}$ Universidade de São Paulo, Faculdade de Filosofia, Ciências e Letras de Ribeirão Preto, Programa de Pós-Graduação em Psicologia. Av. Bandeirantes, 3900, Monte Alegre, 14040-901, Ribeirão Preto, SP, Brasil. Correspondência para/Correspondence to: M.A. SANTOS. E-mail: <masantos@ffclrp.usp.br>.

2 Universidade Federal do Triângulo Mineiro, Instituto de Educação, Letras, Artes, Ciências Humanas e Sociais, Departamento de Psicologia. Uberaba, MG, Brasil.

3 Prefeitura Municipal de Guarujá, Secretaria de Saúde, Programa de Saúde Mental e Atenção Básica. Guarujá, SP, Brasil.

Agradecimentos: Ao Conselho Nacional de Desenvolvimento Científico e Tecnológico pela bolsa de Produtividade em Pesquisa concedida ao primeiro autor. 
Os Transtornos Alimentares (TA), cujas principais expressões psicopatológicas configuram as categorias diagnósticas da Anorexia Nervosa (AN) e Bulimia Nervosa (BN), são temas muito discutidos e pesquisados atualmente devido ao significativo número de adolescentes e jovens adultos que buscam atendimento em clínicas e serviços de saúde. $O$ aumento do interesse por esses quadros também se deve à crescente importância atribuída pela mídia e pela cultura ocidental ao corpo esbelto e magro, que é investido, valorizado e cultuado como padrão ideal de beleza (Andrade \& Santos, 2009; Bigheti et al., 2007; Peres \& Santos, 2011). Do histórico desses transtornos, apreende-se que sua visibilidade aumentou muito nas últimas décadas, devido, em parte, aos estudos que possibilitam um maior reconhecimento de sua incidência e prevalência na população. Estudos buscaram delinear a etiologia da AN e da BN, com o objetivo de identificar fatores de risco para seu aparecimento, bem como comorbidades associadas (Araújo \& Henriques, 2011; Pereira, Trevisol, Quevedo, \& Jornada, 2011; Seixas et al., 2012; Rosa \& Santos, 2011; Weinberg \& Cordás, 2006). A pressão sociocultural para ser magro é referida por vários autores como fator de risco para o desenvolvimento do TA (Polivy \& Herman, 2002; Stice, 1999). Incluem-se, nesse cenário, principalmente, as pressões exercidas pela família, grupos de pares e veículos da mídia (Souza \& Santos, 2007, 2010).

A conceituação da AN e da BN como psicopatologias reproduz as ideias dominantes encontradas no discurso científico e que são reguladas por meio da linguagem (Le Grange, 1999). Os discursos vigentes posicionam as pessoas diagnosticadas com AN e BN de modo particular e acabam sendo legitimados pelo contexto social que os adotam como verdades naturalizadas (Souza, 2011). Na perspectiva do discurso biomédico, os TA são considerados quadros psicopatológicos e não apenas exagero de valores sociais dominantes que permeiam as ações e as adições contemporâneas. Correspondem a perturbações graves e persistentes da conduta alimentar, que têm crescido nas últimas décadas, afetando, sobretudo, adolescentes e jovens mulheres. Nos últimos anos, tem-se observado

394 o aumento do número de homens acometidos
(Andrade \& Santos, 2009), embora a proporção estimada seja de um para cada 10 casos.

A concepção psicológica dos TA é foco de interesse das pesquisas que buscam compreender a dinâmica de personalidade específica dos pacientes que desenvolvem tais psicopatologias (Richards, Berrett, Hardman, \& Eggett, 2006; Souza \& Santos, 2010). A valorização extrema do ideal de magreza pode favorecer sentimentos de depressão, raiva, culpa, estresse e insegurança nas pessoas mais suscetíveis e inseguras (Fortes, 2011; Stice, 1999) que se percebem afastadas do padrão socialmente valorizado para peso e formato corporal. Algumas características de personalidade apontadas como próprias dos TA são: disfunção da percepção corporal, preocupação excessiva com a aprovação social, tentativa de corresponder às expectativas dos pais, sentimento de vazio e sintomas depressivos (Rego, 2004).

Os critérios diagnósticos definidos pelo Diagnostic and Statistical Manual of Mental Desorders - IV - Text Revision (DSM-IV-TR, Manual Diagnóstico e Estatístico das Pertubações Mentais - IV - Revisão de Texto) para a AN são: recusa em manter o peso corporal saudável; medo intenso do ganho de peso ou de se tornar obeso, ainda que esteja abaixo do peso; distúrbio na maneira de perceber a forma física e o peso (distorção da imagem corporal), ou negação da seriedade da atual perda de peso (Associação Americana de Psiquiatria, 2003). Em mulheres, consideram-se como critério diagnóstico a presença de amenorreia (ausência de menstruação) e limitações dietéticas autoimpostas - com um padrão alimentar atípico e acentuada perda de peso induzida e mantida tenazmente -, associadas a temor intenso de engordar.

Os critérios diagnósticos da BN incluem episódio de compulsão alimentar seguido de comportamentos compensatórios (episódio bulímico). Desse modo, a preocupação excessiva com relação ao controle do peso corporal conduz a uma alternância entre hiperfagia e vômitos autoinduzidos - ou uso de métodos purgativos, como manobras compensatórias para o excesso de alimentos ingeridos (Associação Americana de Psiquiatria, 2003). Ao contrário da AN, o peso é mantido na faixa de normalidade ou pode estar um pouco acima do normal (sobrepeso). 
Em decorrência da etiologia multifatorial e da complexidade dos elementos em jogo, tanto no desencadeamento como na manutenção do quadro, o tratamento dos TA envolve abordagem multidisciplinar (Bigheti et al., 2007).

\section{Potencialidades do grupo como dispositivo de tratamento dos TA}

A literatura considera que o tratamento mais eficiente para os TA inclui psicoterapia associada à farmacoterapia. Estudos têm evidenciado que a psicoterapia ajuda a minimizar o sofrimento psicológico e a melhorar a qualidade de vida dos pacientes e de seus familiares (Rego, 2004; Santos, 2006; Stice, 1999).

A psicoterapia de grupo constitui um recurso bastante difundido no contexto do tratamento por proporcionar apoio psicológico centrado nas questões deflagradas pelos TA, como as resistências ao tratamento (psicoterapia, tratamento medicamentoso, rotina de consultas, exames e procedimentos, exposição à tecnologia médica e psicossocial) e às alterações acarretadas no cotidiano e no convívio social, especialmente as intensas repercussões observadas na vida familiar e no ambiente, que despertam ansiedade e sofrimento (Santos, 2006). Nesse sentido, o enquadre grupal fornece um espaço seguro para a expressão emocional e troca de experiências, na medida em que favorece a produção coletiva de significados, que podem ser explorados e canalizados na busca de soluções para os problemas comuns que afetam o cotidiano dos integrantes do grupo de apoio psicológico (Santos, 2006; Scorsolini-Comin, Souza, \& Santos, 2010; Souza \& Santos, 2009, 2010; Yalom, 1970).

A estratégia grupal proporciona o confronto de diferentes percepções e pontos de vista sobre um determinado tema (Rego, 2004), o que pode gerar reflexões múltiplas e, muitas vezes, divergentes ou complementares. Se essas diferentes perspectivas forem acolhidas e elaboradas, promovem o desenvolvimento de recursos, e os participantes podem lidar positivamente com as diferenças e desfrutar de seu potencial transformador, aprendendo por intermédio do outro que vivencia situações e dificuldades semelhantes (Santos, 2006).

Grupos de apoio psicológico são largamente utilizados no contexto da saúde mental como parte da estratégia de reabilitação de pacientes acometidos por transtornos graves e persistentes e que tendem a apresentar um curso progressivo e muitas vezes incapacitante. No cenário dos TA, os objetivos da intervenção em grupo consistem em: proporcionar a expressão de sentimentos relacionados ao transtorno e seu tratamento; contribuir para recuperação da autoestima e constituição de uma autoimagem positiva; fortalecer a vinculação ao tratamento; estimular a recuperação física e emocional e incentivar a comunicação com a equipe de saúde. Além da promoção da melhoria da qualidade de vida, outros objetivos almejados são: adquirir novas habilidades de enfrentamento, o que inclui manejo mais adequado de ansiedade e formas saudáveis de resolução de conflitos, que possam se refletir em situações cotidianas; incentivar a ajuda mútua por meio da partilha, no contexto grupal, de problemas semelhantes; auxiliar a pessoa acometida a lidar com os temores do crescimento e a insegurança gerada pelo escasso sentimento de competência pessoal, uma vez que esses sentimentos estimulam a dependência, a perda de autonomia e o medo do futuro; buscar desfechos mais satisfatórios para suas histórias de dor e sofrimento (Santos, 2006).

\section{Fatores terapêuticos nos grupos com pacientes com TA}

Dentre as abordagens utilizadas para compreender os grupos, notadamente os de apoio psicológico, destaca-se o enfoque dos fatores terapêuticos, que são elementos da psicoterapia de grupo que contribuem para melhorar a condição de um paciente e que podem ser decorrentes tanto das ações do terapeuta do grupo como dos outros membros do grupo e do próprio paciente (Bloch, Reibstein, Crouch, Holroyd, \& Themen, 1979). Os fatores terapêuticos são mediadores de mudança psíquica e designam os elementos comuns a todo tipo de terapia de grupo (Guanaes \& Japur, 2001; 
Jaeger, Seminotti, \& Falceto, 2011; Scorsolini-Comin et al., 2010; Souza, Santos, \& Scorsolini-Comin, 2009).

Foram identificados pelo menos 11 tipos de fatores terapêuticos (Yalom, 1970): instilação de esperança, universalidade, oferecimento de informações, altruísmo, desenvolvimento de técnicas de socialização, comportamento imitativo, catarse, reedição corretiva do grupo familiar primário, fatores existenciais, coesão do grupo e aprendizagem interpessoal. Outros autores (Bloch et al., 1979; Guanaes, 2006; Mackenzie, 1997) descrevem um número menor de fatores: universalidade, instilação de esperança, altruísmo, aceitação (coesão), autorrevelação, catarse, aconselhamento, aprendizado por intermédio do outro, aprendizado interpessoal e autocompreensão (insight). Esses fatores exercem impacto nos participantes e contribuem para sua melhora, ou seja, promovem a redução de sintomas e mudanças de certos padrões de comportamentos desadaptativos que, se reiteradamente repetidos, obstruem o processo de crescimento pessoal.

Os fatores terapêuticos podem ser agrupados em quatro conjuntos: a) Fatores de apoio (universalidade, instilação de esperança, aceitação, altruísmo); b) Fatores de autorrevelação (autorrevelação e catarse); c) Fatores de trabalho psicológico: aprendizado interpessoal e insight; d) Fatores de aprendizado: aconselhamento e aprendizado por intermédio do outro (Mackenzie, 1997). Os fatores de apoio, que constituem o foco do presente estudo, foram privilegiados porque são os que correspondem ao provimento de apoio social, cuja importância na reabilitação e promoção da saúde tem sido amplamente reconhecida pela literatura. Sua presença está no uso cotidiano que os participantes fazem da rede de apoio familiar, social e institucional.

Dentre os fatores de apoio, destacam-se, por sua relevância no cenário do tratamento dos TA, a universalidade e a instilação de esperança. A universalidade diz respeito ao sentimento de compartilhar com outras pessoas dificuldades similares, o que favorece a identificação com os demais participantes do grupo, fortalece a autoconfiança e minimiza as de esperança está relacionada ao reconhecimento, por parte dos pacientes com TA, de que existem alternativas, até então insuspeitadas, para atenuar ou solucionar os problemas que os afligem. Essa experiência de vislumbrar caminhos possíveis produz alívio do sofrimento e incrementa a autoestima rebaixada.

Compreender os fatores terapêuticos mobilizados no grupo pode auxiliar o coordenador a ampliar as possibilidades de intervenção com pacientes com TA (Souza et al., 2009). Esses fatores não devem ser entendidos como instâncias teóricas de análise ou categorias, mas como importante instrumento para compreender o funcionamento do grupo, sua manutenção e desenvolvimento ao longo do tempo, o que contribui para a construção das condições favoráveis à mudança.

A partir do exposto, o objetivo deste estudo foi analisar a produção dos fatores terapêuticos de apoio presentes em um grupo para pacientes com diagnóstico de TA. Acredita-se que o conhecimento desses fatores possibilite compreender alguns dos mecanismos psicológicos que auxiliam a promover mudanças no comportamento alimentar dos pacientes submetidos ao enquadre grupal.

\section{Método}

Trata-se de um estudo descritivo, exploratório, de corte transversal, com enfoque de pesquisa qualitativa. Foi conduzido em condições naturalísticas, no contexto de um serviço de saúde especializado em TA, situado em um hospital universitário. O serviço oferece atendimento multidisciplinar a pessoas com diagnóstico de $\mathrm{AN}$ e BN, encaminhadas pelos diversos serviços públicos de saúde de um município do interior paulista, bem como de outras cidades da região noroeste de São Paulo e de outros estados da federação. Considerado referência no tratamento dos TA, o serviço especializado, ao dar acolhimento à demanda espontânea e referenciada, constitui um campo de atividades de assistência, ensino e pesquisa para investigadores e alunos de graduação e pós-graduação. 
Dentre as atividades oferecidas pela equipe multidisciplinar, incluem-se as diferentes modalidades de atendimento. Os pacientes participam de consultas individuais com médicos nutrólogos (residentes e adidos ao serviço), psiquiatra, nutricionistas, psicólogos, grupos de apoio psicológico e de orientação nutricional a pacientes e familiares, avaliação nutricional, psicológica e psiquiátrica, tratamento medicamentoso, psicoterapia individual e assistência psicológica às famílias.

Durante o período de coleta dos dados, encontravam-se em tratamento 42 pacientes. A maior parte da casuística (39) era constituída por mulheres adolescentes e jovens, o que requer o acompanhamento dos pais ou responsáveis legais durante os atendimentos. No que concerne ao tempo de diagnóstico, observou-se uma amplitude de variação de um a 12 anos. O rendimento econômico das famílias variou de baixo a médio. Os cuidadores eram atendidos em um grupo específico para os familiares que se reunia simultaneamente ao grupo de pacientes.

O encontro do grupo de apoio psicológico às pessoas com TA cadastradas no serviço era semanal. As sessões tinham duração de $1 \mathrm{~h} 30 \mathrm{~min}$, e o grupo era coordenado por dois psicólogos em esquema de cocoordenação. Configurava-se como um grupo aberto, sem agenda de temas preestabelecidos. O critério de inclusão dos participantes no estudo foi o mesmo de indicação para o serviço e para a modalidade de atendimento em grupo, isto é, ter recebido diagnóstico de AN ou BN, estar em seguimento regular no serviço e estar preservado do ponto de vista das capacidades cognitivas, auditivas e de comunicação.

Este estudo foi aprovado pelo Comitê de Ética do hospital universitário no qual foi feita a coleta de dados. Para assegurar o anonimato dos participantes, seus nomes foram omitidos e serão designados pela letra $\mathrm{P}$ acompanhada dos números correspondentes (P1, P2, P3...).

No decorrer de 10 sessões consecutivas, os participantes do grupo foram sistematicamente solicitados a colaborar voluntariamente com a investigação. Essa participação implicava dar anuência para que o encontro grupal, uma atividade inserida na rotina do serviço, pudesse ser audiogravado. Quando todos os participantes do grupo estavam de acordo com esse procedimento e não manifestavam desconforto, solicitava-se a assinatura do Termo de Consentimento Livre e Esclarecido. Na sequência, o gravador era ligado e colocado no centro da arena grupal. Seguindo-se essa sistemática de abordagem, obteve-se anuência unânime dos participantes de 10 encontros grupais. Posteriormente, foram selecionadas, por meio de sorteio, duas sessões audiogravadas.

O sorteio de duas sessões objetivou extrair um "recorte" aleatório, isto é, não intencional ou enviesado, a fim de evidenciar a possibilidade de análise dos fatores terapêuticos elencados independentemente da sequência das sessões ou do processo grupal completo. Ademais, como se trata de um grupo aberto - ou seja, a composição de seus membros varia de sessão para sessão -, não teria sentido empreender uma análise do processo grupal. Em consonância com a literatura, que aponta que os fatores terapêuticos podem ser empiricamente observados, o propósito foi abarcar a possibilidade de tais elementos emergirem em sessões isoladas. Desse modo, o escopo é destacar o fenômeno (fatores terapêuticos) e não o processo grupal que se delineia ao longo das sessões que ocorrem durante um período de tempo determinado.

Da primeira sessão analisada, participaram seis pacientes. Na segunda sessão escolhida, estiveram presentes cinco, sendo que uma das integrantes havia comparecido também ao encontro anterior. Dessa maneira, compareceram ao segundo encontro quatro novas participantes, totalizando, assim, dez participantes nas duas sessões selecionadas. As participantes eram do sexo feminino, com idades que variaram de 14 a 25 anos. A maioria (seis) era estudante e residia com a família de origem. As demais eram profissionalmente inativas. Seis tinham antecedentes de internação hospitalar em função do agravamento do quadro de TA. O tempo de tratamento no serviço variou de três meses a dez anos.

O material transcrito foi, preliminarmente, submetido à pré-análise, com uma leitura exaustiva 
com o objetivo de familiarizar-se com os conteúdos. Em seguida, foram identificados os trechos de falas das participantes que evidenciavam a ativação dos fatores terapêuticos de apoio. Na sequência do procedimento de análise, foram delimitados núcleos de sentido que permitiram dar legibilidade aos dados, considerando os objetivos propostos (Bogdan \& Biklen, 1982).

\section{Resultados}

Na análise do material transcrito, foram buscadas evidências da emergência da universalidade e da instilação de esperança. O primeiro fator terapêutico de destaque foi a universalidade, caracterizada como a tomada de consciência pelo paciente que vivencia seu sofrimento de forma isolada de que há outras pessoas em situação semelhante à sua, com problemas e conflitos análogos aos seus. Essa descoberta provoca sensação de alívio, que repercute em melhora da autoestima e redução do estigma social associado ao quadro. O paciente rompe com seu aparente isolamento e se mostra propenso a se engajar na busca de sua melhora, com possibilidade de estabelecer intercâmbio social franco e honesto. O senso de universalidade é a consequência do processo de comparação social que ocorre naturalmente em grupos (Santos, 2006).

Nas sessões analisadas, foi possível destacar algumas sequências em que esse fator comparece nas falas dos pacientes, como a narrativa encontrada na primeira sessão, na qual uma das participantes comenta: "mas aí eu vi que tem mais pessoas, né, que tem mais pessoas passando pela mesma situação, e que às vezes está até numa situação mais difícil do que a minha" (P2).

Pode-se notar uma sensação de alívio da paciente por descobrir que existem outras pessoas convivendo com problema que ela julga semelhante ou até mais difícil do que aquele que ela enfrenta. A fala de outra participante corrobora tal percepção: "é, e também pra mim foi bom também, saber que tantas pessoas que têm também e que não sou só eu. Porque eu me achava esquisita antes" (P1).
Assim, ao reconhecerem outras pessoas que sofrem com sintomas que, geralmente, são considerados extravagantes pelo meio social, as pacientes podem, no grupo de apoio, experimentar a possibilidade de se verem como "normais". Esse é um passo importante para a aceitação do problema, um desafio que precisa ser enfrentado no tratamento desses transtornos, uma vez que o paciente não se percebe doente nas fases iniciais, o que o leva a mostrar, via de regra, uma tenaz resistência à terapêutica instituída (Santos, 2006).

A experiência de se sentir diferente da maioria das pessoas é um tema recorrente nos encontros. O reconhecimento de pontos de semelhança nas dificuldades enfrentadas no cotidiano funciona como elemento atenuador desse sentimento de estranheza. Além disso, é unificador das experiências individuais das participantes, que geralmente são desqualificadas e estigmatizadas pelo meio social e familiar. A universalização possibilita, em um primeiro momento, que os sentimentos e comportamentos adotados no dia a dia apareçam aos olhos do outro - esse outro que é personificado nos demais membros do grupo - como algo familiar e aceitável, ou pelo menos que não suscitem julgamento, crítica e condenação moral. A possibilidade de romper o isolamento social a partir da identificação com outro participante pode ser notada no excerto de fala a seguir: "eu tava me sentindo tão assim diferente das pessoas. Eu não conhecia ninguém que tinha e eu não conhecia aqui ainda" (P1).

A partir dessa tomada de consciência de que outros também vivenciam experiências semelhantes, fortalecem-se não apenas os laços de identificação entre as participantes, como será mais bem visto a seguir, como também a atribuição de um importante significado ao grupo, na medida em que ele pode aglutinar, sob um mesmo espaço, pessoas com vivências semelhantes, dispostas a explorarem estratégias para lidar com problemas do cotidiano. Sendo assim, as participantes não apenas podem conhecer pessoas que passam pelo mesmo processo, como também significar o grupo como espaço que as congrega ao abrir a possibilidade do encontro genuíno. Nesse encontro, é possível engen- 
drar a construção coletiva de sentidos sobre o estar doente e refletir sobre suas implicações. Conhecer pessoas em situação comparável parece favorecer a horizontalidade, que possibilita lidar com situações e espaços nos quais se pode exercitar as habilidades de comunicação e de confidência de experiências íntimas:

"Eu passei por uma fase assim [estabelecendo uma comparação com o que outra participante havia dito], de eu começar a comer e já me sentir cheia" (P3).

"É porque é assim, eu entendo o que ela sente porque eu também sou assim. Eu falo assim para mim mesma: Eu não vou conseguir" (P4).

Por meio desses excertos de fala, é possível compreender que a universalidade, como fator terapêutico favorecido pelo estar em um grupo de apoio psicológico, também possibilita a visão da diferença, na medida em que cada participante apresenta vivências particulares, ainda que sejam relacionadas ao mesmo transtorno. Nesse sentido, as manifestações sintomáticas são entendidas apenas como o elo que costura suas experiências em comum, mas cujas expressões são configuradas de forma singular por cada participante em seu contexto de vida. O desenvolvimento da empatia entre as componentes do grupo pode ser percebido na medida em que elas se identificam com as demais e se colocam na posição de buscar ajuda, ao mesmo tempo em que passam a acolher umas às outras a partir do compartilhamento de experiências e oferta de apoio. Assim, há assunção de posicionamentos que conferem ao grupo um caráter singular, não como um local no qual todas concordam com todas, mas em que podem fazer um exercício de se aproximarem da experiência alheia e compreenderem as nuanças de seu universo (Souza \& Santos, 2009; Scorsolini-Comin, Amato, \& Santos, 2006). Ao visitar esse lugar ocupado por outrem, é possível que a paciente tome consciência de suas próprias limitações, bem como se aproprie de seus recursos, e passe a ressignificar sua própria experiência de sofrimento, produzindo novos sentidos para o tratamento e a vida em geral.
Na segunda sessão analisada, surgiram também relatos que evidenciam a tomada de consciência entre as participantes de que outras pessoas vivenciavam situações de vida semelhantes, o que pode proporcionar acolhimento e compreensão mútua e favorecer maior coesão grupal. Na medida em que a universalização dessas experiências desperta a consciência de que essas mulheres têm recursos potenciais para também ajudar outras pessoas que passam por situações de dificuldade, pondera-se que isso possa conduzi-las à assunção de uma postura de encorajamento e potencialidade diante do problema, promovendo o desenvolvimento de recursos internos capazes de produzir efeitos satisfatórios ao longo do tratamento. Sendo assim, não se trata apenas de desabafar, promovendo a catarse que permita o alívio imediato da carga emocional mobilizada pelos conflitos mal resolvidos. Não basta apenas compartilhar histórias e experiências, é preciso poder significá-las como veículos de desenvolvimento e amadurecimento emocional: "tudo o que vocês passaram, eu também passei, de uma forma ou de outra" (P5). "Eu entendo o que vocês estão dizendo porque eu já passei por tudo isso" (P3). "Realmente, você tem razão, aconteceu isso comigo..." (P2).

Outro fator terapêutico elencado neste estudo é a instilação de esperança, que pode ser compreendida como a possibilidade que a participante com TA desenvolve de olhar para si mesma a partir de outra perspectiva. Ocorre quando a pessoa tem a sensação de que existe alguma possibilidade de alívio e melhora para seus problemas. Ter esperança de mudar seu próprio destino reforça o engajamento na psicoterapia de grupo e reduz o risco de rompimento precoce do vínculo e de interrupção do tratamento, diminuindo a ansiedade e fortalecendo o enfrentamento das dificuldades (Bloch et al., 1979; Bloch, 1986; Souza \& Santos, 2009; Yalom, 1970). Isso é de importância vital no manejo terapêutico do TA, considerada a baixa resolutividade do tratamento, com altas taxas de abandono e recidiva. A sensação de que existe alguma possibilidade de alívio e de melhora para o sofrimento decorrente das situações problemáticas enfrentadas no cotidiano e de que é possível atingir a 
meta desejada desperta otimismo e fortalece a confiança quanto ao seu próprio potencial de mudança. Isso encoraja a participante a encarar com menos temor o futuro, predispondo-a a despender maior esforço na troca ativa de experiências com os demais. Assim, o membro do grupo pode experimentar os efeitos do suprimento de suas necessidades afetivas por meio das relações interpessoais, rompendo de modo gradual a tendência ao isolamento social.

Na primeira sessão analisada, pôde-se identificar o desejo relatado por uma das participantes de "se cuidar mais", o que é de substancial importância no contexto do TA, dado o deficit notável de autocuidado: "acho que é um maior estímulo para eu estar me cuidando, me aceitando, tentando ter mais saúde, mais cuidado comigo" (P1).

Também ganhou força no grupo a possibilidade de se ressignificarem momentos vivenciados que estimulam as participantes a darem continuidade ao tratamento, como podemos notar no seguimento narrativo de uma paciente com AN: "essa semana eu consegui ir num rodízio de pizza" (P4).

Quando uma paciente com AN do tipo restritivo relata no grupo que se permitiu ir a um rodízio de massas e se alimentar diante de outras pessoas, há que se destacar a superação de uma imensa barreira pessoal, na medida em que as pessoas acometidas por tal transtorno tendem a se isolar socialmente, uma vez que não mantêm os padrões alimentares compartilhados pela coletividade, além de se sentirem inadequadas em decorrências da visão distorcida da sua imagem corporal. Mais do que isso, no que concerne ao objetivo deste estudo, a participante sentiu-se segura para, no grupo, revelar tal episódio, celebrado por ela e pelas demais como uma vitória, uma conquista que serve de exemplo construtivo para aquelas que vivenciam restrições semelhantes. O potencial de afetar o outro, assim como de ser afetado a partir de sua presença, falas e comportamentos, amplia os efeitos mutativos do enquadre grupal. Nesse sentido, também está presente nas falas um incremento da confiança quanto ao próprio potencial para obter 400 mudanças, a despeito das dificuldades encontradas, como é possível notar nos excertos a seguir: "porque eu tenho certeza que eu vou ficar bem, mas eu não estou me sentindo bem assim!" (P1). "Porque assim, vendo assim as melhoras que eu tive, eu até admiro o que eu consegui aqui" (P2).

Na segunda sessão investigada no presente estudo, o senso de otimismo estava presente na fala da participante P2, que utilizou o espaço grupal para destacar a melhora percebida em outra participante desse encontro: "e é muito bom vir aqui e encontrar... e ver que ela tá muito mais solta, muito mais aberta... Parabéns!" (P2).

A ponderação de que a outra participante estava melhor acaba não apenas servindo como incentivo para que as demais também se empenhem em melhorar como legitima e valida a transformação compartilhada; desse modo, o grupo possibilita a instilação de esperança na medida em que se reconhecem os esforços e os êxitos de cada participante engajada na construção coletiva do processo de mudança. Ao tornar pública tal conquista, a participante passa a universalizar os ganhos advindos também de sua participação no grupo de apoio. Não se pode afirmar se a melhora se deve especificamente ao seu engajamento no grupo, mas pelas falas é possível perceber que essa modalidade de tratamento é percebida como um recurso que acompanha as pacientes em momentos de crise, assim como nos assomos de esperança, funcionando como espaço de acolhimento e de desenvolvimento pessoal. Ao verbalizar a melhora obtida, uma participante pôde auxiliar outra que vivenciava seu próprio processo de enfrentamento das dificuldades, como se pode perceber nas seguintes falas: "eu acho que é a força de vontade, vontade de querer melhorar, pelo menos comigo é assim..." (P6). "Esse grupo assim, é uma maneira da gente ajudar, e por isso que me ajuda a fazer o meu tratamento" (P7).

No excerto de fala apresentado a seguir, também fica evidente que o grupo é percebido como oportunidade de apoio mútuo, entendido como recurso útil para fazer frente às dificuldades de reinserção social. "Porque, sabe, ali tinha alguém me incentivando, tinha alguém me dando força, dizendo assim: cê vai conseguir! E eu acreditava 
que você, pensando assim, de uma forma mais positiva, tentando pensar de uma forma mais positiva, pode realmente conseguir" (P5).

A participante P5 relata que estava se sentindo envolvida e conectada na rede social constituída pelo grupo e que essa rede a afetava positivamente. Nesse caso, a instilação de esperança funcionou como um recurso destacado no tratamento justamente por possibilitar um sentido de envolvimento e de continuidade (Bloch et al., 1979) do qual o grupo se torna fiel depositário. Assim, o tratamento passa a ser compreendido como um processo que se desenvolve ao longo do tempo, assim como os vínculos que são estabelecidos e fortalecidos no grupo, o que permite colocar em cena os dramas individuais das participantes (Santos, 2006), que compartilham histórias pungentes de fracasso e superação. As trocas de experiência podem tanto se referir a tentativas esboçadas de melhora como corresponder a pequenos ganhos cotidianos relacionados à difícil convivência com o TA.

\section{Discussão}

A análise dos relatos produzidos na situação naturalística do grupo evidenciou, em um primeiro momento, que o grupo é percebido como um espaço privilegiado para oferecer suporte emocional, informativo e de convivência para as pessoas acometidas pelos TA. Os relatos coligidos sugerem que o grupo seja significado como um espaço em que as participantes possam se reconhecer na experiência das outras e fazer um exercício de reflexão acerca de suas dificuldades, o que pode facilitar a obtenção de insights acerca do lugar que os sintomas assumem em suas vidas (Souza \& Santos, 2007, 2010; Yalom, 1970). Na situação grupal, os laços sociais podem ser fortalecidos, o que fomenta um ambiente propício para potencializar transformações. Cada participante pode se ver a partir de outra perspectiva, a partir dos múltiplos olhares lançados pelas demais componentes. Há uma produção coletiva de significados, que podem ser explorados e canalizados na busca de soluções para os problemas comuns que afetam o cotidiano de todos
(Santos, 2006). Com essas diretrizes em mente, o coordenador do grupo busca estimular a recuperação física e emocional da pessoa com TA, conduzindo-a ao contato com o outro, que também a constitui. Os fatores de universalidade e de instilação de esperança ajudam a minimizar a sensação de desconforto com o tratamento e possibilitam recuperar a autoestima danificada, de modo a atenuar o impacto da autoimagem comprometida devido à grave distorção da imagem corporal. Essas questões devem ser consideradas para a compreensão das situações de vulnerabilidade psicossocial da pessoa acometida por TA. Assim, a presença dos fatores terapêuticos de apoio no espaço grupal fornece indícios a serem considerados no planejamento da assistência psicológica e na organização dos cuidados em saúde de um modo geral.

Uma implicação dos resultados deste estudo é a necessidade de que os coordenadores do grupo sejam devidamente treinados de modo a incrementarem sua sensibilidade à identificação dos fatores terapêuticos presentes nos encontros grupais. Um olhar mais atento a essa abordagem pode assegurar um manejo grupal apropriado, mais responsivo às demandas grupais e individuais e que explore o potencial do grupo como espaço privilegiado de interações que podem promover a transformação de seus integrantes. Nesse sentido, um dos focos de investigações futuras poderia ser o manejo do grupo pelos profissionais de saúde, haja vista que a assunção dos fatores terapêuticos depende, sobretudo, da qualidade desse manejo, da fundamentação teórica que sustenta as intervenções e da facilitação promovida pelos coordenadores. Obviamente, essas questões não puderam ser desenvolvidas neste estudo por extrapolarem o objetivo proposto. Contudo, pode-se apontar para a necessidade de uma reflexão: o aparecimento dos fatores terapêuticos no grupo não é um fenômeno isolado e independente do manejo operado pelos coordenadores e demais profissionais envolvidos.

No contexto analisado, os resultados corroboram o pressuposto teórico de que os fatores terapêuticos podem ativar mecanismos eliciadores de mudança, que são favorecidos pelo enquadre grupal a partir do desenvolvimento de recursos para 
lidar com as situações de vulnerabilidade ligadas aos quadros psicopatológicos graves (Mackenzie, 1997). Notadamente, os fatores de apoio acabam tendo uma repercussão amplificada quando se trata de uma psicoterapia de apoio que se configura no formato de grupo. A assunção da universalidade e da esperança não deve ser compreendida como característica exclusiva desses grupos, como se definissem, a priori, o perfil de um grupo de apoio. Vale reiterar que é o manejo do grupo, a fundamentação teórica e a destreza dos coordenadores envolvidos nesse contexto que podem promover a assunção desses elementos em um contexto terapêutico de mudança. É a instrumentalização que o psicoterapeuta de grupo é capaz de fazer desses elementos que permite que eles possam ser evocados não apenas como fatores estanques, mas como indicadores dinâmicos da qualidade da assistência e de como o grupo vem se desenvolvendo de modo a constituir um espaço potencial no qual se fomenta a melhora da condição psíquica de seus participantes.

Nas análises empreendidas, pode-se constatar o modo como os fatores terapêuticos de apoio estiveram presentes no espaço grupal a partir das narrativas das participantes. Ainda que não se possa afirmar, a partir dos dados analisados, que tais elementos estariam repercutindo na mudança dos hábitos alimentares, nota-se um movimento em direção ao comportamento adaptativo e ao fortalecimento da motivação para buscar a superação do transtorno ou, pelo menos, a redução dos danos produzidos pelas manifestações sintomáticas. Além disso, notou-se que o grupo assumiu um caráter de promoção de ressocialização, o que permitiu resgatar alguns laços sociais, seriamente prejudicados pelo adoecimento, além de encorajar o exercício de papéis e o desenvolvimento de habilidades necessárias para o enfrentamento das condições adversas.

Desse modo, o presente estudo fornece pistas que permitem evidenciar, juntamente com o auxílio de análises complementares, que o grupo pode ser um espaço privilegiado para investigar os efeitos do apoio mútuo percebido por pacientes em
Obviamente, análises suplementares são necessárias, considerando a possibilidade de existirem outras condições que seriam mobilizadoras de processos de mudança no grupo, o que deve ser investigado em estudos futuros. Considerando que, em seu contexto de vida, as pessoas que desenvolvem TA são muitas vezes alvo de incompreensão, preconceito e discriminação - o que acaba cristalizando estereótipos que perpetuam estigmas e delimitam zonas de exclusão social -, definir em que circunstâncias o apoio é percebido por elas como significativo pode, sob uma perspectiva ampliada de saúde, contribuir para redimensionar o tratamento segundo suas necessidades subjetivas.

\section{Referências}

Andrade, T. F., \& Santos, M. A. (2009). A experiência corporal de um adolescente com transtorno alimentar. Revista Latino-Americana de Psicopatologia Fundamental, 12(3), 454-68.

Araújo, M. X., \& Henriques, M. I. R. S. (2011). Que "diferença faz a diferença" na recuperação da anorexia nervosa? Revista de Psiquiatria Clínica, 38(2), 71-76.

Associação Americana de Psiquiatria. (2003). DSM-IV-TRTM - Manual diagnóstico e estatístico de transtornos mentais: texto revisado ( $4^{\mathrm{a}} \mathrm{ed}$.). Porto Alegre: Artmed.

Bigheti, F., Santos, M. A., Ribeiro, R. P. P., Oliveira, E. A., Unamuno, M. R. L., \& Santos, J. E. (2007). Transtornos alimentares: anorexia e bulimia nervosas: uma abordagem didática. In Associação Brasileira de Enfermagem. Programa de atualização em enfermagem: saúde do adulto: ciclo 2, módulo 2 (pp.9-44). Porto Alegre: Artmed.

Bogdan, R., \& Biklen, S. K. (1982). Qualitative research for education. Boston: Allyn and Bacon.

Bloch, S. (1986). Therapeutic factors in group psychotherapy. In A. J. Frances, \& R. E. Hales. Psychiatric Update Annual Review (Vol.5, pp.678-698). Washington, D.C: American Psychiatric Press.

Bloch, S., Reibstein, J., Crouch, E., Holroyd, P., \& Themen, J. (1979). A method for the study of therapeutic factors in group psychotherapy. British Journal of Psychiatric, $134,257-263$.

Fortes, I. (2011). Anorexia: o traço da obstinação na clínica psicanalítica. Revista Latino-Americana de Psicopatologia Fundamental, 14(1), 83-95.

Guanaes, C. (2006). A construção da mudança em terapia de grupo. São Paulo: Vetor.

Guanaes, C., \& Japur, M. (2001). Fatores terapêuticos em um grupo de apoio para pacientes psiquiátricos 
ambulatoriais. Revista Brasileira de Psiquiatria, 23(3), 134-140.

Jaeger, M. A. S., Seminotti, N., \& Falceto, O. G. (2011). O grupo multifamiliar como recurso no tratamento dos transtornos alimentares. Revista de Psiquiatria do Rio Grande do Sul, 33(1), 20-27.

Le Grange, D. (1999). Family therapy for adolescent anorexia nervosa. Journal of Clinical Psychology, 55(6), 727-39.

Mackenzie, K. R. (1997). Time-managed group psychotherapy: Effective clinical applications. Washington: American Psychiatric Press.

Pereira, L. N. G., Trevisol, F. S., Quevedo, J., \& Jornada, L. K. (2011). Eating disorders among health science students at a university in Southern Brazil. Revista de Psiquiatria do Rio Grande do Sul, 33(1), 14-19.

Peres, R. S., \& Santos, M. A. (2011). Técnicas projetivas na avaliação de aspectos psicopatológicos da anorexia e bulimia. Psico USF, 16(2), 185-192.

Polivy, J., \& Herman, C. P. (2002). Causes of eating disorders. Annual Review of Psychology, 53(1), 187-213.

Rego, M. G. S. (2004). A psicodinâmica em anoréxicas gêmeas monozigóticas. In S. R. Busse (Org.), Anorexia, bulimia e obesidade (pp.31-99). São Paulo: Manole.

Richards, P. S., Berrett, M. E., Hardman, R. K., \& Eggett, D. L. (2006). Comparative efficacy of spirituality, cognitive, and emotional support groups for treating eating disorder inpatients. Eating disorders: The Journal of Treatment \& Prevention, 14(5), 401-415.

Rosa, B. P., \& Santos, M. A. (2011). Comorbidade entre bulimia e transtorno de personalidade borderline: Implicações para o tratamento. Revista Latino-Americana de Psicopatologia Fundamental, 14(2), 268-282.

Santos, M. A. (2006). Sofrimento e esperança: grupo de pacientes com anorexia e bulimia nervosas. Medicina, 39(3), 386-401.

Scorsolini-Comin, F., Amato, A. M., \& Santos, M. A. (2006). Grupo de apoio para casais pretendentes à adoção: a espera compartilhada do futuro. Revista da SPAGESP, 7(2), 40-50.

Scorsolini-Comin, F., Souza, L. V., \& Santos, M. A. (2010). A construção de si em um grupo de apoio para pessoas com transtornos alimentares. Estudos em Psicologia (Campinas), 27(4), 467-478.

Seixas, C., Miranda-Scippa, A., Nery-Fernandes, F., Andrade-Nascimento, M., Quarantini, L. C., Kapczinski, F., \& Oliveira, I. R. (2012). Prevalence and clinical impact of eating disorders in bipolar patients. Revista Brasileira de Psiquiatria, 34(1), 66-70.

Souza, L. V. (2011). Construindo cuidado: a relação com o profissional de saúde nas práticas discursivas de pessoas diagnosticadas com transtornos alimentares (Tese de doutorado não-publicada). Universidade de São Paulo.

Souza, L. V., \& Santos, M. A. (2007). Anorexia e bulimia: conversando com as famílias. São Paulo: Vetor.

Souza, L. V., \& Santos, M. A. (2009). A construção social de um grupo multifamiliar no tratamento dos transtornos alimentares. Psicologia: Reflexão e Crítica, 22(3), 317-26.

Souza, L. V., \& Santos, M. A. (2010). A participação da família no tratamento dos transtornos alimentares. Psicologia em Estudo, 15(2), 285-294.

Souza, L. V., Santos, M. A., \& Scorsolini-Comin, F. (2009). Percepções da família sobre a anorexia e bulimia nervosa. Vínculo, 6(1), 1-9.

Stice, E. (1999). Clinical implications of psychosocial research on bulimia nervosa and binge-eating disorder. Journal of Clinical Psychology, 55(6), 675-83.

Weinberg, C., \& Cordás, T. A. (2006). Do altar às passarelas: da anorexia santa à anorexia nervosa. São Paulo: Annablume.

Yalom, I. (1970). The theory and practice of group psychotherapy. New York: Basic Books.

Recebido em: 11/11/2010

Versão final em: 26/4/2012

Aprovado em: 15/5/2012 
